\title{
Identidade e imagem por meio do processo de comunicação: um estudo da percepção do associado de uma cooperativa de crédito
}

Identity and image through the process of communication: a perception study of a credit union affiliated

\section{Resumo}

Dada a frequente confusão entre instituições financeiras cooperativas e instituições financeiras bancárias, este trabalho cumpre a finalidade de identificar a formação da imagem, que resulta da transmissão de mensagens de suas características próprias (identidade), de uma cooperativa de crédito em seu público alvo, os associados. Para atingir o objetivo proposto realizou-se uma investigação caracterizada como qualitativa e quanto aos procedimentos técnicos como um estudo único de caso em uma cooperativa filiada ao sistema SICREDI. Os dados foram coletados por meio de entrevistas, observação participante e análise de documentos. Os resultados apontam a percepção das falhas que impactam nos processos de comunicação, de construção da imagem e de formação da identidade pelos associados, como a falta de unidade entre as cooperativas filiadas ao sistema, as diferenças culturais e o perfil dos associados, assim como a inaptidão dos colaboradores na apresentação da marca e do cooperativismo ao associado.

Palavras-chave: Cooperativismo; Crédito; Identidade; Imagem; Comunicação

\begin{abstract}
Knowing the frequent confusion between cooperative financial institutions and banking financial institutions, this work has the purpose of identifying image formation, which results from the transmission of messages of their own characteristics (identity), of a credit cooperative in their target public, the members. In order to achieve the proposed objective, a qualitative investigation was carried out as regards the technical procedures as a single case study in a Cooperative affiliated to the SICREDI system. Data were collected through interviews, participant observation and document analysis. The results highlight the perception of the flaws that have an impact on the processes of communication, image building and identity formation of the Cooperative, such as the lack of unity between the cooperatives affiliated to the system, the cultural differences and the profile of the associates, as well as the lack of employees in presenting the brand and the cooperativism to the member.
\end{abstract}

Keywords: Cooperativism; Credit; Identity; Image; Communication

Recebido: 19/09/2017 Aceito: 02/10/2017

Vitor Sanches Breda ${ }^{1}$

${ }^{1}$ Especialização em andamento em MBA em Gestão de Cooperativas de Crédito. Universidade de São Paulo - USP 


\section{Introdução}

$\mathrm{C}$ ooperativa se define "como uma associação autônoma de pessoas unidas voluntariamente para satisfazer suas necessidades e aspirações econômicas, sociais e culturais em comum através da criação de uma empresa de propriedade conjunta e gerida de forma democrática" (OIT, 2002 apud LOPES, 2012) propondo a universalização do empreendedorismo e instrumentalizando-o por meio da associação de interesses dos cooperados (LOPES, 2012). Ampliam-se fundamentos da economia capitalista como a cooperação de interesses, a capitalização empreendedora e a liberdade de trabalho.

Desde a criação da primeira cooperativa de crédito no Brasil, em 1902, o cooperativismo se difunde graças aos princípios que o norteiam, como a gestão democrática e o interesse pela comunidade, de modo a constituir sua identidade, levando em conta o fato de que esta é a forma como uma empresa se organiza e funciona (MEINEN, 2012). Isso exemplifica-se com a padronização proposta nos anos 90 às cooperativas de crédito que, posteriormente, vieram compor o Sistema Sicredi. Aqquela época foi desenvolvida uma identidade única para as cooperativas já conhecidas individualmente, a fim de consolidar e expandir o cooperativismo de crédito na mídia.

Acrescente-se que, em um contexto de frequentes mudanças e de grande concorrência, as cooperativas de crédito destacam-se no mercado cooperativo frente ao mercado competitivo, pela estruturação de um empreendimento econômico coletivo para o atendimento das necessidades próprias dos associados. A cultura cooperativista, pouco divulgada no Brasil, "representa um obstáculo ao crescimento desse modelo de negócios, especialmente em mercados competitivos, como o financeiro" (SERVIÇO NACIONAL DE APRENDIZAGEM DO COOPERATIVISMO, 2016).

No entanto, frequentemente as cooperativas são vistas como uma forma alternativa financeiramente melhor para a utilização de produtos e serviços bancários, perdendo características que compõem sua essência. Tal fato, em grande parte, está associado à imagem que o público-alvo tem da organização. O conceito de imagem é exterior à organização, apesar de sua formação estar intimamente ligada à sua identidade. Assim, a imagem percebida pelos associados, construída em um processo dinâmico que se associa à educação cooperativa, relaciona-se ao desenvolvimento da identidade das cooperativas, que expressa sua missão e suas responsabilidades sociais.

É importante identificar e compreender a imagem que o público tem da organização. No caso do estado de São Paulo há certa dificuldade em entender a cooperativa como uma sociedade de pessoas que, além de usufruírem de seus produtos e serviços, também devem desempenhar importantes funções, dado o fato de que são donos do negócio e tem responsabilidades específicas, como a autorização para realização de despesas, aprovação do resultado anual, decisão do direcionamento das sobras, participação das reuniões e assembleias de núcleo que compõem, além da físcalização das atividades da cooperativa, levando em consideração apenas a oferta de produtos e serviços. Tal fato repercute em diversas situações como o "processo assemblear", por exemplo, que depende exclusivamente da presença dos associados exercendo seu poder voto nas decisões da cooperativa.

Nesse sentido, o objetivo geral deste trabalho é identificar o impacto da comunicação na imagem percebida pelos associados da cooperativa. Em outras palavras, trata de identificar as dificuldades em sua compreensão como uma instituição financeira cooperativa, sociedade de pessoas, que oferece soluções, produtos e serviços assim como as instituições financeiras caracterizadas como sociedades de capital, apresentado, porém, consideráveis distinções. Como objetivos específicos destacam-se a identificação das dificuldades na compreensão dos associados como sociedade de pessoas e não de capital, seus deveres responsabilidades e; analisar a identidade comparando-a às das cooperativas do sul do país, considerando características e objetivos do sistema Sicredi no âmbito nacional.

Como procedimento metodológico adotou-se um estudo de caso único, qualitativo e exploratório, realizado em uma cooperativa filiada ao sistema Sicredi, sediada no município de Araraquara/SP. Os dados foram coletados no período de 12 meses, por meio de observação participante, entrevistas com 04 
colaboradores e a análise de documentos, como o regulamento dos programas Crescer e Pertencer.

\section{Fundamentação teórica}

Sendo a identidade uma realidade imaterial ou conceitual extrovertente, dirigida ao exterior, destinada a projetar-se, em termos de imagem, sobre o público a que respeita o interesse econômico da empresa, tal efeito é realizado e depende da comunicação ou da informação como meios reais de transmissão dos caracteres ou elementos da identidade aos seus destinatários. (...) Consistindo em um estado de natureza psicológica, de ideia ou sentimento formado pela recepção ou introversão dos elementos ou dados da identidade das empresas transmitidos através da comunicação ou da informação, é à imagem que se dirige e projeta todo o valor da identidade" (FAVEIRO, 2003).

\subsection{Identidade}

A palavra identidade origina-se do latim "idem" e tem como objetivo mostrar, reconhecer a natureza dos seres e das coisas. Assim, a identidade organizacional pode ser entendida, como resultado da relação produtiva entre discurso e imagem, ou seja, o que surge da afinidade entre as intenções do discurso e as impressões do receptor (LASBECK, 2007). Afinidade esta que se dá pelas semelhanças e diferenças geradas e esperadas por ambos os lados da relação. Administrar a identidade, portanto, corresponde a coordenar a produção, a reprodução e a reformulação do discurso à vista dos dados obtidos pela pesquisa de imagem.

Caldas e Wood Junior (1997) apontam que a identidade organizacional pode surgir na forma pela qual a organização é percebida (imagem externa), por aqueles com quem ela interage, como, por exemplo, clientes e fornecedores e também seus membros internos, especialmente seus dirigentes, de forma compartilhada, correspondendo a uma percepção de si mesma ou autopercepção ou autoimagem. Pode surgir, ainda, na definição da razão de ser, finalidade ou propósito da entidade ou do grupo de indivíduos, de modo que a identidade representaria esse propósito existencial, sendo a representação cognitiva mantida pelos membros da organização.
Afirmando que a identidade organizacional compreenderia as crenças compartilhadas pelos membros sobre o que é central, distintivo e duradouro na organização, Albert e Wheten (1985, apud MACHADO-DA-SILVA; NOGUEIRA, 2000) apresentam três critérios que, em conjunto, são suficientes para definir a identidade como conceito científico. São eles o critério de centralidade, que "aponta as características vistas como essência da organização", o da distintividade, que pode ser traduzido de diversas maneiras, tais como os objetivos organizacionais estratégicos, a missão, as proposições ideológicas, os valores, a filosofia ou a cultura particular e que "aponta os elementos que distinguiria uma organização das outras com as quais poderia ser comparada" e o de continuidade temporal que "ressalta as características estáveis no tempo".

Elsbach (1996, apud MACHADO-DASILVA; NOGUEIRA, 2000) sublinha que a identidade de uma organização reflete seus atributos centrais e diferenciadores, incluindo seus valores essenciais, cultura organizacional, modos de desempenho e de agir e produtos. Nesse sentido, denomina-se de identificação organizacional o processo entendido como a extensão pela qual as pessoas se entrelaçam psicologicamente com a organização e reconhecem, na sua identidade, a identidade organizacional (FERNANDES et al., 2009).

A Figura 1 demonstra a identidade organizacional como o conjunto de atributos que emergem da cultura e prática organizacional e funcionam como um sistema de representação que esta cria para si própria e para os outros (RUÃ̃), 2005). 


\section{Figura 1-A identidade organizacional}

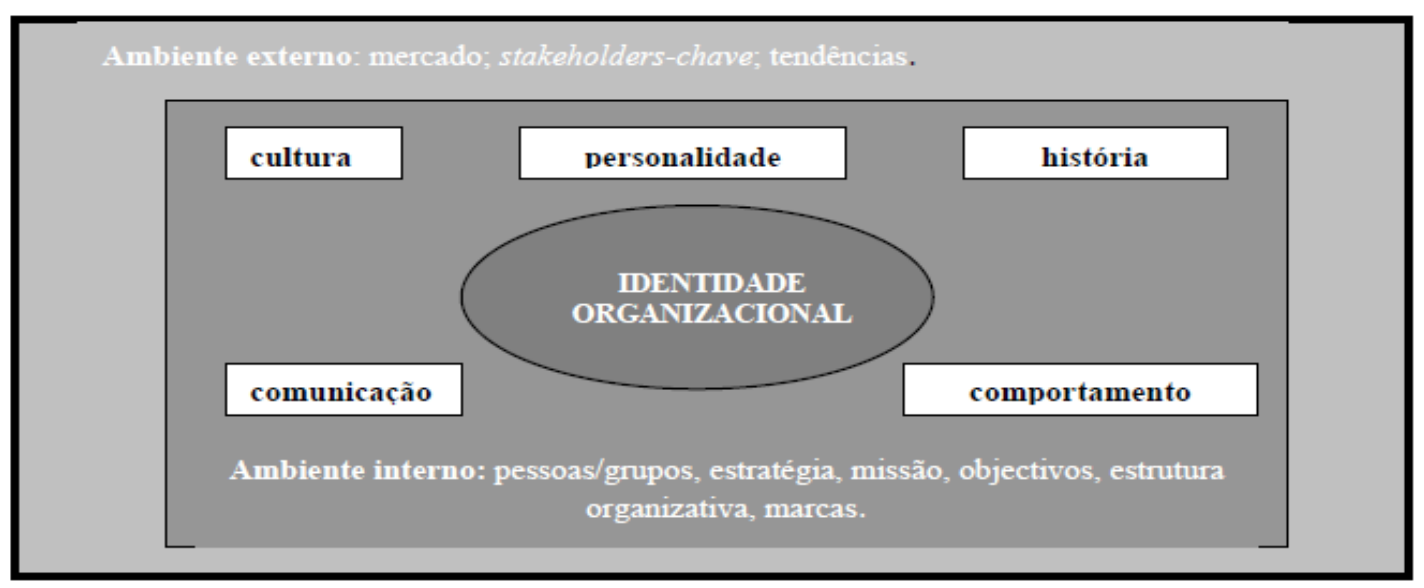

Fonte: RUÃO (2005)

Com base no exposto, a identidade organizacional é vista como a expressão das percepções das pessoas sobre o significado da organização. Pode ser compreendida, então, como resultante dos esquemas cognitivos ou percepção a respeito dos atributos diferenciadores e essenciais da organização, incluindo seu posicionamento no contexto (status) e comparações relevantes com outros grupos ou organizações. Ademais, de acordo com Ruão (2001), a projeção dessa identidade, ou tentativa de dominação, faz-se por processos comunicativos, que colocam em relação emissores e receptores da mensagem institucional. Por esse meio, e atendendo aos conteúdos promotores do sentido oficial, as organizações determinam os papéis dos autores sociais que com ela interagem, e promovem a partilha de objetivos, estratégias e responsabilidades.

\subsection{Imagem}

Este estudo aborda o conceito de imagens mentais, que se formam por um receptor em decorrência dos discursos organizacionais, de anúncios publicitários, de sua experiência pessoal ou de diversos estímulos visuais, acústicos, olfativos e táteis de um determinado emissor (MITCHELL, 1986).

Kotler (1998) demonstra que a imagem organizacional é a forma com que um indivíduo vê uma organização, afirmando, ainda, que diferentes pessoas podem ter diferentes imagens de uma mesma organização. Esta impressão que um indivíduo ou um grupo de pessoas tem de uma organização é inconsciente. As impressões podem ser verdadeiras ou falsas, reais ou imaginárias. Certas ou erradas, as imagens guiam e formam comportamento. As empresas precisam identificar forças e fraquezas de sua imagem e empreender ações para melhorar sua imagem (Barich e Kotler, 1991, apud BATISTA, 2004).

No processo de formação da imagem organizacional o público é o agente ativo e a organização o agente passivo, uma vez que a imagem não pertence a organização, ou seja, é o público quem detém a imagem da organização. Dessa forma, de acordo com Carissimi (2001), a formação da imagem é resultado de todas as experiências, crenças, posições, conhecimentos, sentimentos e impressões que as pessoas têm a respeito da organização, como também de seus produtos e serviços, e de suas personalidades, bem como é uma impressão suposta sobre a organização, tida em comum por um grupo de pessoas, além de ser resultante, também, de uma informação que uma pessoa ou um grupo tem de uma organização.

Nas atividades comerciais, por exemplo, o objetivo da imagem criada é obter o maior grau possível de adesão e empatia por parte dos diversos públicos de interesse. Em vista disso, uma imagem favorável ou desfavorável não tem um fim em si mesma. Ela se torna imprescindível, portanto, no processo dinâmico de gestão da identidade. Destacase também a facilidade em se modificar uma imagem graças a um esforço de comunicação. Assim, pode-se modificar uma percepção arraigada de uma organização, como também uma imagem positiva, com a maior facilidade e rapidez, pode se converter em outra totalmente negativa. 
Por isso, de acordo com Lasbeck (2007), nas práticas comerciais, busca-se primordialmente alargar os espaços da identidade, que podem ser traduzidos por graus incertos e não totalmente previsíveis de afinidade entre produção e recepção, entre os interesses, desejos, e necessidades de quem produz e os interesses, desejos, e necessidades de quem consome. Esse incerto grau precisa ser ocupado proativamente pelo discurso das organizações; deve estar presente em suas preocupações estratégicas e constituir um espaço virtual de experimentações. Isso possibilita elementos que transformem imagens em reputação e reputação em novas imagens, criando um ciclo renovável de expectativas duradouras e satisfações provisórias.

\subsection{Comunicação}

Entendendo comunicação como um processo que envolve a transmissão de uma mensagem de um emissor, que a codifica, a um receptor, que a decodifica, com um determinado objetivo, que apresenta uma fonte e é transmitida por um canal de comunicação, verifica-se que comunicação é o uso da linguagem em um ato de discurso que organiza a circulação da fala numa comunidade social, ou seja, trata-se da produção de um discurso em uma situação de comunicação pautada em uma determinada informação (CHARAUDEAU, 2006).

De acordo com Brandão (2007), a comunicação organizacional, que abrange as diferentes formas de relacionamento e interação entre a organização e seus públicos, visa criar relacionamentos com os diversos públicos e construir uma identidade e uma imagem dessas instituições, sejam elas públicas e/ou privadas, desempenha um importante papel no que diz respeito a formação de uma imagem positiva da organização diante do público, como forma de manutenção de seus negócios, o que evidencia sua importância em face ao novo cenário globalizado. Assim, a comunicação organizacional, que permeia todas as ações organizacionais, viabiliza a construção da cultura e identidade da organização, assim como de sua imagem externa, já que marca seu estilo próprio e forma pela qual ela projeta-se externamente (RESTREPO,1995).

À vista disso, o processo de comunicação organizacional pode ser dimensionado como informação, enquanto caracterizadora das operações próprias de cada organização, sua missão, visão, valores, princípios e políticas, como divulgação, tornando-a pública, como gerador de relações voltadas a formação, a socialização e/ou reforço de processos culturais, como os programas Crescer e Pertencer do estudado Sistema Cooperativo Sicredi e como participação, ou seja, a abertura de comunicação do outro.

Além de viabilizar o cumprimento dos objetivos e metas organizacionais, "estratégias organizacionais, marketing corporativo, propaganda corporativa, comunicação interna e externa, entre outros, que constituem um grupo heterogêneo de atividades de comunicação" (RIEL, 1995), a comunicação organizacional, de acordo com Kunsch (1997), deve constituir-se num setor estratégico, agregando valores e facilitando os processos interativos, por meio das Relações Públicas, da organização com os seus diferentes públicos, a opinião pública e a sociedade em geral.

Dadas as recentes e aceleradas transformações e contextos cada vez mais complexos, onde as organizações precisam buscar novas lógicas de gestão para enfrentar a competitividade, hoje, é necessário entender a complexidade que envolve a informação e os processos comunicacionais na gestão estratégica das organizações (CARDOSO, 2006). Então, percebe-se que a comunicação organizacional tem a finalidade de harmonizar as comunicações externa e interna, bem como criar um clima motivador dentro de uma organização ou unidades de informação que atua com indivíduos.

\section{Cooperativismo de crédito}

\subsection{Cooperativismo de crédito: cenário}

De acordo com Meinen (2012), desde seu surgimento no século XIX, em Rochdale, na Inglaterra, após a Revolução Industrial, com a primeira Cooperativa moderna, a Sociedade dos Probos de Rochdale, o cooperativismo se desenvolve sob uma mesma orientação doutrinária com princípios e valores definidos. Estes, de maior abrangência, precedem e originam aqueles, que traduzem a solidariedade, a liberdade, a democracia, a equidade, a igualdade, a responsabilidade, a honestidade, a transparência e a responsabilidade socioambiental e levam à prática no meio cooperativo. 
O cooperativismo não visa lucros, os direitos e deveres de todos são iguais e a adesão é livre e voluntária, ou seja, visa às necessidades do grupo, aliando o economicamente viável ao ecologicamente correto e ao socialmente justo com a finalidade de promover o desenvolvimento econômico e o bemestar social de todos (BCB, 2016).

O Banco Central do Brasil (2016), supervisor do cooperativismo de crédito no país, define Cooperativa de Crédito como uma instituição financeira formada pela associação de pessoas para prestar serviços financeiros exclusivamente aos seus associados, respeitando valores como ajuda mútua e equidade. Os cooperados são ao mesmo tempo donos e usuários da cooperativa, participando de sua gestão e usufruindo de seus produtos e serviços. Cada um destes cooperados representa um voto, independentemente da sua cota de participação no capital social, de modo que as decisões são tomadas coletivamente e os resultados obtidos são distribuídos de forma justa e igualitária, na proporção de sua participação na cooperativa.

A preocupação com valores e ideais humanitários visualiza-se pelas definições propostas pela Aliança Cooperativa Internacional (ACI), associação independente e não governamental que congrega organizações representativas do cooperativismo nos cincos continentes (OCB, 2014, p. 10) e pela Organização Internacional do Trabalho (OIT), que trabalha fortemente para a expansão e a legitimação do segmento, dando maior visibilidade política ao movimento cooperativista (OCB, 2014, p. 11). Isso distingue tais instituições quando comparadas a outras iniciativas de caráter empresarial. De acordo com a primeira "cooperativa é uma associação autônoma de pessoas, unidas voluntariamente, para atender as suas necessidades e aspirações econômicas, sociais e culturais comuns, através de uma empresa coletiva e democraticamente controlada" (Congresso Centenário da ACI. Manchester, Inglaterra, setembro de 1995). A segunda, por seu turno, define Cooperativa como "uma associação de pessoas que se unem voluntariamente para realizar um objetivo comum, através da formação de uma organização administrada e controlada democraticamente, realizando contribuições equitativas para o capital necessário e aceitando assumir de forma igualitária os riscos e benefícios do empreendimento no qual os sócios participam ativamente" (Recomendação $\mathrm{n}^{\mathrm{o}}$ 127).

Este trabalho destaca os princípios da adesão voluntária e livre, da gestão democrática, da autonomia e independência, e da educação, formação e informação entre os sete definidos pela Aliança Cooperativa Internacional (ACI), que são linhas orientadoras através das quais as cooperativas levam à prática os seus valores.

O princípio da adesão voluntária e livre, de acordo com a OCB (2014) demonstra que o acesso é livre a qualquer indivíduo que deseje se associar a uma cooperativa, nos termos da lei e do estatuto social, considerando-se aqui a questão da aptidão, como também que a manifestação de adesão compete ao próprio interessado, não se cogitando que alguém possa ser compelido a ingressar ou a permanecer na sociedade. Este princípio tem a ver imediatamente com os valores da liberdade e da igualdade.

Ressaltando os valores da democracia, da igualdade, da transparência e da responsabilidade, o princípio da gestão democrática, acolhido especialmente pelo art. $4^{\circ}$, V e VI; art. 38 , caput e $\$ 3^{\circ}$; 37, III, e art. 42, da Lei Cooperativista, e pelo art.1.094, V e VI, do Código Civil, demonstra que o controle da cooperativa é realizado por seus membros, que são convidados a compartilhar todas as decisões (OCB, 2014).

A sociedade cooperativa, quanto à sua governança, deve guiar-se pelos princípios próprios da democracia, que pressupõe a atuação responsável de todos os membros. Votar e ser votado, de acordo com as condições estatutárias, constituem direitos e, por consequência, deveres basilares do associado. Participar da vida da cooperativa é condição inarredável para o seu sucesso, cumprindo a quem está na liderança assegurar todas as condições para a prática desse direito-dever, incluindo a instituição de canais e outros mecanismos adequados e transparentes de acesso a informações e participação dos cooperados (MEINEN, 2012).

O princípio da autonomia e independência, que se refere aos valores da democracia, transparência e honestidade, diz respeito à blindagem da cooperativa para evitar a ingerência política ou de qualquer outra força exterior ao meio social (sindical, classista, etc.), visto que por ser iniciativa concebida pela conjugação de esforços do quadro social 
(membros) e moldar-se pela autogestão (governo pelos próprios meios), o sucesso ou o insucesso do empreendimento afetam unicamente associados; em segundo lugar, em razão de a gestão ser exclusividade dos associados, não se cogita de influência externa, especialmente para assegurar privilégios em detrimento da coletividade de cooperados (MEINEN, 2012).

Por fim, o princípio da educação, formação e informação, condição indispensável para a designação de cooperativa, de acordo com o sistema OCB (2014) e Meinen (2012), diz respeito a promoção da educação e da formação de seus associados, atores internos, associados, dirigentes (conselheiros e diretores) e demais colaboradores, inclusive os prestadores de serviços terceirizados - e a conscientização do público em geral, para que estes contribuam com o crescimento do empreendimento e haja uma boa pratica cooperativista. Este princípio que se relaciona imediatamente com os valores da transparência e da responsabilidade demonstra que a comunicação é essencial para que haja uma adesão mais expressiva às entidades cooperativas, especialmente de públicos dos médios e grandes centros urbanos.

No cooperativismo de crédito, então, esse fenômeno de descompromisso e descaso é recorrente em unidades nas quais não se fazem os esforços relacionados ao cumprimento deste princípio. $\mathrm{O}$ ideal, aliás, é que haja programas de formação que considerem o perfil dos diferentes atores internos. No caso dos associados, é indispensável que a assunção de cargos eletivos na cooperativa seja antecedida de uma passagem por um bem estruturado mecanismo de preparação para o mundo cooperativo (MEINEN, 2012).

\subsection{Cooperativismo de crédito no Brasil}

As primeiras cooperativas de crédito brasileiras surgiram em meados do século XIX, tendo em vista os ideais cooperativistas presentes em nossa história desde o tempo das missões. São elas a Sociedade Econômica dos Funcionários Públicos de
Ouro Preto (MG), cooperativa de consumo, habitação e crédito, fundada em 1889, e a primeira cooperativa de crédito propriamente dita, a Caixa de Economia e Empréstimos Amstad, fundada em 28 de dezembro de 1902 no município de Nova Petrópolis/RS, atual Sicredi Pioneira RS. Seu crescimento credita-se à sua composição na forma de um modelo sistêmico que se baseava na integração horizontal e vertical das cooperativas, cuja ausência foi uma das maiores causas da fragilização do movimento em períodos precedentes (MEINEN, 2012).

O cenário positivo então criado proporcionou o surgimento de novas cooperativas de crédito rural e crédito mútuo (urbano), e de uma confederação do setor, a Confederação Brasileira das Cooperativas de Crédito - CONFEBRAS, em 1986. Com isso, as cooperativas conquistaram um cenário de maior abertura normativa frente ao Banco Central do Brasil permitindo o surgimento dos bancos cooperativos, como o Banco Cooperativo Sicredi, constituído em 1995 na cidade de Porto Alegre/RS, com a finalidade de integrar as cooperativas ao sistema nacional de pagamentos, gerir a liquidez sistêmica e prover soluções corporativas de negócios (MEINEN, 2012) e das confederações dos principais sistemas de crédito hoje existentes.

O Quadro 1 demonstra a participação de mercado das instituições financeiras brasileiras. Nota-se que em dezembro de 2016 as Cooperativas Financeiras Brasileiras representavam uma participação de mercado de $3,57 \%$, dado que o total de ativos por elas administrados é de R $\$ 296$ bilhões. Tais dados comprovam a sua $6^{\text {a }}$ posição no ranking das maiores instituições financeiras do país. 
Quadro 1- Participação das Instituições Financeiras Brasileiras (base 12/2016)

\begin{tabular}{|c|c|c|c|c|c|c|c|c|}
\hline Instituigão financeira & Ativos Totais & $\begin{array}{l}\text { \%de } \\
\text { Ativos } \\
\text { Totais }\end{array}$ & Depósitos & $\begin{array}{c}\text { \% de } \\
\text { Depósitos }\end{array}$ & $\begin{array}{l}\text { Patrimônio } \\
\text { Liquido }\end{array}$ & $\begin{array}{c}\text { \% do } \\
\text { Patrimônio } \\
\text { Líquido }\end{array}$ & $\begin{array}{l}\text { Operaçōes de } \\
\text { Crédito }\end{array}$ & $\begin{array}{l}\text { \% das } \\
\text { Operapöes de } \\
\text { Crédito }\end{array}$ \\
\hline Banco do Brasil & 1.436 .765 .379 & $17,33 \%$ & 447.949 .127 & $20,97 \%$ & 77.040 .362 & $11,69 \%$ & 622.312 .167 & $19,46 \%$ \\
\hline Itaú & 1.331 .840 .737 & $16,06 \%$ & 369.390 .258 & $17,29 \%$ & 129.934 .938 & $19,72 \%$ & 440.538 .388 & $13,78 \%$ \\
\hline Caixa Econômica Federal & 1.256.172.164 & $15,15 \%$ & 513.098 .225 & $24,02 \%$ & 27.179 .943 & $4,12 \%$ & 696.727 .941 & $21,79 \%$ \\
\hline Bradesco & 1.081.374.701 & $13,04 \%$ & 235.821 .329 & $11,04 \%$ & 101.221 .022 & $15,36 \%$ & 344.946 .899 & $10,79 \%$ \\
\hline Santander & 705.061 .403 & $8,50 \%$ & 146.962 .603 & $6,88 \%$ & 60.008 .577 & $9,11 \%$ & 212.803 .654 & $6,66 \%$ \\
\hline Cooperativismo Financeiro $* *$ & 295.901 .295 & $3,57 \%$ & 141.876 .258 & $6,64 \%$ & 39.186 .275 & $5,95 \%$ & 109.254 .405 & $3,42 \%$ \\
\hline Safra & 148.391 .008 & $1,79 \%$ & 12.588 .744 & $0,59 \%$ & 9.507 .705 & $1,44 \%$ & 42.865 .462 & $1,34 \%$ \\
\hline Citibank & 72.024 .491 & $0,87 \%$ & 19.374 .446 & $0,91 \%$ & 8.411 .261 & $1,28 \%$ & 13.988 .425 & $0,44 \%$ \\
\hline Banrisul & 68.235 .459 & $0,82 \%$ & 42.782 .849 & $2,00 \%$ & 6.441 .339 & $0,98 \%$ & 27.150 .479 & $0,85 \%$ \\
\hline Banco do Nordeste & 46.321 .128 & $0,56 \%$ & 10.607 .320 & $0,50 \%$ & 3.362 .495 & $0,51 \%$ & 12.373 .958 & $0,39 \%$ \\
\hline Total do SFN & 8.290 .875 .227 & & 2.136 .563 .602 & & 658.951 .392 & & 3.197 .491 .576 & \\
\hline
\end{tabular}

Fonte: BACEN (2016)

\footnotetext{
* Consideradas apenas instituições financeiras de varejo que possuem agências de atendimento

** Incluídos os Bancos Cooperativos

*** Depósitos: não inclusos títulos e valores mobiliários e letras financeiras.
}

\subsection{O Sistema Sicredi}

O Sistema de Crédito Cooperativo Sicredi, referência internacional pelo modelo de atuação em sistema, que permite ganhos de escala e aumenta o potencial das cooperativas de crédito para exercer a atividade em um mercado no qual estão presentes grandes conglomerados financeiros, compreende o conjunto de 121 cooperativas de crédito singulares filiadas, que operam com uma rede de atendimento com 1.501 pontos e cinco cooperativas centrais, acionistas da Sicredi Participações S.A. bem como as empresas e entidades por esta controladas, entre elas uma Confederação, uma Fundação, um Banco Cooperativo, uma Administradora de Cartões, uma Administradora de Consórcios e uma Corretora de Seguros, que atuam no mercado sob a marca Sicredi e adotam um padrão operacional único (SICREDI, 2011).

Como sistema cooperativo, a missão do Sicredi é valorizar o relacionamento, oferecer soluções financeiras para agregar renda e contribuir para a melhoria da qualidade de vida dos associados e da sociedade. Sua visão é ser reconhecido pela sociedade como instituição financeira cooperativa, comprometida com o desenvolvimento econômico e social dos associados e das comunidades, com crescimento sustentável das cooperativas, integradas em um sistema sólido e eficaz. Como valores do Sicredi têm-se a preservação irrestrita da natureza cooperativa do negócio; o respeito à individualidade do associado; a valorização e desenvolvimento das pessoas; a preservação da instituição como sistema; o respeito às normas oficiais e internas, e a eficácia e transparência na gestão.

3.4 Distinções entre instituições financeiras cooperativas e bancárias

Embora as cooperativas de crédito e os bancos convencionais convivam sob uma unidade regulatória e supervisora, suas origens e seus propósitos são distintos. O Quadro 2 possibilita vislumbrar os aspectos relevantes que diferenciam as duas referidas iniciativas societárias. 


\begin{tabular}{|c|c|}
\hline Sociedade Cooperativa & Sociedade de Capital (Banco) \\
\hline $\begin{array}{l}\text { Objetivo: estruturação de um empreendimento } \\
\text { econômico coletivo para o atendimento das } \\
\text { necessidades próprias dos associados }\end{array}$ & $\begin{array}{l}\text { Objetivo: exploração de uma atividade econômica com fins } \\
\text { lucrativos }\end{array}$ \\
\hline Quórum para assembleia = número de associados & Quórum para assembleia = capital representado \\
\hline $\mathrm{O}$ voto tem peso igual para todos & O poder é exercido na proporção do número de ações \\
\hline $\begin{array}{l}\text { É vedada a transferência de quotas-parte do } \\
\text { capital subscrito ou integralizado a terceiros }\end{array}$ & Não é vedada a alienação ou transferência de capital a terceiros \\
\hline $\begin{array}{l}\text { Resultado distribuído proporcionalmente às } \\
\text { operações e serviços }\end{array}$ & Resultado distribuído proporcionalmente ao capital integralizado \\
\hline Capital variável & Capital fixo \\
\hline $\begin{array}{l}\text { A utilização das operações e dos serviços } \\
\text { oferecidos é condição básica para o sócio }\end{array}$ & $\begin{array}{l}\text { A utilização das operações e dos serviços pela empresa não é } \\
\text { condição básica para o sócio }\end{array}$ \\
\hline As decisões são partilhadas entre muitos & As deliberações são concentradas \\
\hline $\begin{array}{l}\text { Os administradores-líderes são do meio } \\
\text { (associados) }\end{array}$ & Os administradores são terceiros (homens do mercado \\
\hline O usuário é o próprio dono (cooperado) & O usuário das operações é mero cliente \\
\hline $\begin{array}{l}\text { Toda a política operacional é decidida pelos } \\
\text { próprios usuários/donos (associados) }\end{array}$ & $\begin{array}{l}\text { O usuário não exerce qualquer influência na definição dos } \\
\text { produtos e na sua precificação }\end{array}$ \\
\hline $\begin{array}{l}\text { Não podem distinguir: o que vale para um, vale } \\
\text { para todos (art. } 37 \text { da Lei } n^{\circ} 5.764 / 71 \text { ) }\end{array}$ & Podem tratar distintamente cada usuário \\
\hline Não discriminam, servindo a todos os públicos & Preferem o público de maior renda e as maiores corporações \\
\hline Possuem forte atuação nas comunidades remotas & $\begin{array}{l}\text { Priorizam os grandes centros (embora não tenham limitação } \\
\text { geográfica) }\end{array}$ \\
\hline $\begin{array}{l}\text { A mercancia não é cogitada (art. } 79, \text { Lei } n^{\circ} \\
5.764 / 71)\end{array}$ & Tem propósitos mercantilistas \\
\hline $\begin{array}{l}\text { O preço das operações e dos serviços tem como } \\
\text { referência os custos e como parâmetro as } \\
\text { necessidades de reinvestimento }\end{array}$ & $\begin{array}{l}\text { A remuneração das operações e dos serviços não tem } \\
\text { parâmetro/limite }\end{array}$ \\
\hline O relacionamento é personalizado & Atendem em massa, priorizando o auto serviço \\
\hline $\begin{array}{l}\text { Comprometidas com as comunidades e os } \\
\text { usuários }\end{array}$ & Não têm vínculo com a comunidade e o público-alvo \\
\hline Desenvolvem-se pela cooperação & Avançam pela competição \\
\hline $\begin{array}{l}\text { O lucro está fora do seu objeto tanto pela sua } \\
\text { natureza quanto por determinação legal (art. } 3^{\circ} \text {, } \\
\text { lei }{ }^{\circ} 5.764 / 71 \text { ) }\end{array}$ & Visam ao lucro por excelência \\
\hline $\begin{array}{l}\text { O excedente é distribuído entre os usuários, na } \\
\text { proporção das operações individuais, reduzindo } \\
\text { ainda mais o preço final pago pelos cooperados e } \\
\text { aumentando a remuneração de seus investimentos }\end{array}$ & O resultado é de poucos donos (nada é dividido com os clientes) \\
\hline $\begin{array}{l}\text { São reguladas pela Lei Cooperativista e por } \\
\text { legislação própria }\end{array}$ & $\begin{array}{l}\text { No plano societário, são reguladas pela Lei das Sociedades } \\
\text { Anônimas }\end{array}$ \\
\hline
\end{tabular}

Fonte: MEINEN (2012); FUNDAÇÃO SICREDI (2016).

De acordo com Meinen (2012), a cooperativa de crédito nasce da vontade e da necessidade de um grupo de pessoas, que se congregam (elegem uma sociedade ou um fórum comum) para troca (exercício da mutualidade) de soluções. Este grupo de pessoas, associados, tem mais benefícios à medida que a cooperativa cresce e mais produtos e serviços utilizam, ao passo que os bancos convencionais surgem da convicção unilateral do dono do capital (ou do negócio) - sem qualquer consulta ao usuário - com o único objetivo de ampliar (rentabilizar) o capital investido.

O controle das instituições cooperativas é democrático, uma vez que cada pessoa representa um único voto, independente do capital social (somatório das quotas-parte) que possui e seus resultados são 
denominados sobras, quando positivos, e perdas, quando negativos. Quando há sobras, estas são distribuídas entre os associados e são proporcionais às operações realizadas por cada um, o que não ocorre nas demais instituições financeiras, que não tem aumento de seu capital, já que este é dividido em um número limitado de ações. Além disso, quanto mais os associados investem na cooperativa e a valorizam, mais ela será solidária com a comunidade local ou com o segmento em que está inserida.

\subsection{Educação: Programas sociais}

O programa Crescer, de acordo com as cartilhas do Programa de Formação Cooperativa Crescer do sistema Sicredi, Contribuindo para o crescimento coletivo (2011) e Compartilhando decisões e resultados (2011) destina-se aos associados das cooperativas e à comunidade em geral, e tem como um de seus desafios o aprimoramento do processo de organização do quadro social, fazendo com que o associado entenda sua responsabilidade nas decisões e resultados da cooperativa. O Programa de Formação Cooperativa do Sistema de Crédito Cooperativo Sicredi objetiva qualificar a participação dos associados na gestão e no desenvolvimento das cooperativas, uma vez que o Sicredi busca difundir a cultura da cooperação e do cooperativismo, acreditando ser essencial criar condições para que os cidadãos possam capacitar-se e assim crescer.

\section{Figura 2 - Estrutura do Programa Crescer}

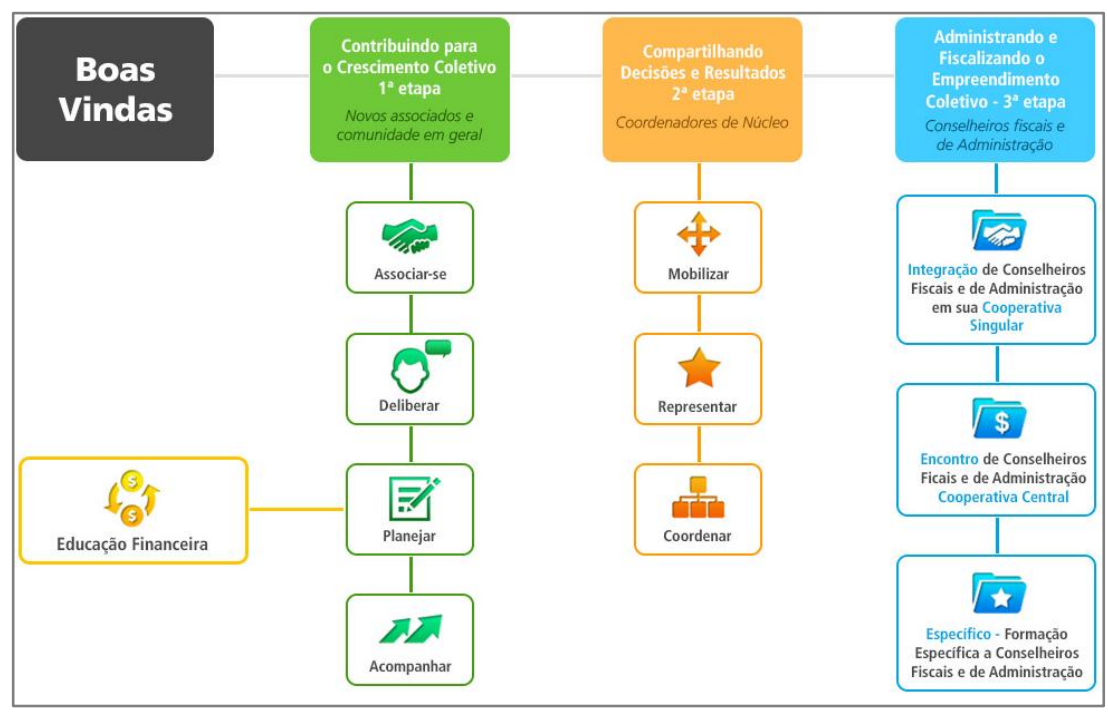

Fonte: SICREDI, 2014.

Enquanto o Programa Crescer atua na formação do associado o Programa Pertencer tem o
A metodologia do Programa Crescer fundamenta-se em metas de aprendizagem, que correspondem a conhecimentos que se espera que cada associado tenha para participar diretamente da cooperativa e nas avaliações, de caráter formativo, que compõem o processo avaliativo com a finalidade de observar se os conteúdos foram aprendidos ao final de cada percurso (FUNDAÇÃO SICREDI, 2014).

Além de preparar os associados para atuarem como donos do Sicredi, o Crescer representa a preocupação do Sistema com a sucessão nas cooperativas, visto que é preciso conhecer uma cooperativa, saber suas diferenças em relação a uma sociedade anônima, a uma sociedade limitada, e assim por diante, para administrar uma cooperativa. Assim, visa à preparação de lideranças, associados responsáveis pela manutenção e pela gestão estratégica das sociedades cooperativas. O Programa derivará para a formação dos responsáveis pelo processo de gestão das cooperativas, os presidentes, vice-presidentes e conselheiros, que precisam ter uma formação mais específica para a gestão empresarial de suas cooperativas.

O Programa Crescer viabiliza a possibilidade de desempenho das funções ou cargos estatutários, visto que sua conclusão é obrigatória. A capacitação prepara o associado para decidir, de forma consciente, o futuro da sua cooperativa (FUNDAÇÃO SICREDI, 2014). 
cooperativa. Alinhado com o documento Governança Cooperativa publicado em fevereiro de 2009 pelo Banco Central do Brasil, o qual aponta diretrizes e mecanismos para o fortalecimento das cooperativas de crédito entre os quais a capacitação dos dirigentes e colaboradores e o aumento da transparência e do controle, o Pertencer modifica a forma como os associados participam do "processo assemblear" de sua cooperativa. Para o sistema Sicredi (2016) e Meinen (2012) o Programa amplia a participação dos associados, que têm a oportunidade de votar nos núcleos. Em regiões onde a área de atuação da cooperativa abrange uma grande extensão geográfica, esta reformulação permite que mais gente participe das decisões, sem precisar se deslocar até o local da assembleia geral. Em outras palavras, percebe-se que com a existência dos núcleos, é possível contar com a participação da totalidade dos associados no processo decisório, uma vez que não há necessidade de reunir todos ao mesmo tempo.

Em resumo, verifica-se que o sucesso e a perenidade de uma cooperativa são relacionados à participação dos associados, administradores da cooperativa, na sua gestão e no seu desenvolvimento. Acompanhar e fiscalizar as ações dos gestores, seja por meio da participação em reuniões e assembleias, seja por meio da atuação dos conselheiros de Administração e Fiscal e dos coordenadores de núcleo eleitos, faz parte das boas práticas de governança, constituindo-se um direito e um dever do associado. Portanto, manifestar sua opinião nos fóruns de discussão organizados pela cooperativa, deliberativos ou não, é a melhor forma de ampliar a sensação de pertencimento e propriedade e garantir que seus interesses serão ouvidos pelos dirigentes.

\section{Trabalho de campo}

A opção pela execução deste trabalho decorre das inquietações de seu autor no que se refere ao não entendimento de grande parcela dos associados do seu papel de dono do negócio, e, consequentemente, do não cumprimento de seus deveres e responsabilidades. A experiência obtida durante o referido período de trabalho levou à busca de explicações sobre as causas que dificultam o entendimento do funcionamento da Cooperativa e da atuação dos associados como donos e não apenas usuários. Estas percepções resultam das dificuldades verificadas na conquista de quórum para realização de assembleias, na formação de coordenadores de núcleo e conselheiros, na utilização de vocabulário adequado pelos cooperados, desinteresse destes pelos assuntos da Cooperativa, entre outras coisas, que resumem sua reduzida, ou nula participação.

\subsection{Estudo de caso}

O estudo de caso, quantitativo e exploratório, realizado na cooperativa estudada no período de 12 (doze) meses buscou demonstrar, por meio da análise dos documentos do sistema Sicredi e da cooperativa paulista, do período de exercício de trabalho e das entrevistas realizadas com uma assessora de comunicação, uma diretora executiva, uma gerente de agência e um analista de controles internos perceber como ocorre construção da identidade da organização, assim como identificar a imagem que os associados têm da cooperativa a qual são quotistas.

A imersão realizada na regional da cooperativa, nas quatro agências e nas assembleias realizadas no período, apresentou justificativas sobre as causas que dificultam o entendimento do funcionamento da cooperativa e da atuação dos associados como usuários dos serviços e não quotistas, ou seja, sua educação cooperativa.

\subsection{Resultados e desafios}

Ao longo do estudo do caso identificaram-se falhas nos processos de comunicação, de formação da imagem e da construção da identidade da Cooperativa. Desse modo, é necessário corrigir as falhas identificadas para que seja formada "uma imagem positiva da organização diante do público" (BRANDÃO, 2007).

A falta de unidade entre as 118 cooperativas filiadas é uma das falhas identificadas. A autonomia garantida a cada uma das cooperativas leva a construção da imagem de uma instituição pequena e sem força, que aparenta não ter as mesmas capacidades de outras instituições financeiras. Isso se deve aos distintos processos de comunicação de cada uma das cooperativas. Cada uma destas tem a independência de criar suas campanhas e suas peças 
publicitárias, assim como utilizar diferentes meios de comunicação com seu público.

A inaptidão dos colaboradores no que se refere à sua estrutura e as atividades as quais executa, ao apresentar o cooperativismo de crédito, seus processos e suas distinções em relação à outras instituições financeiras tem um impacto direto na formação da imagem e da construção da identidade pelo associado, visto que são criadas impressões que não representam a imagem do sistema. A ausência de instrução ou mesmo a não utilização das ferramentas disponíveis acarreta em uma comunicação imprecisa entre cooperativa e associado e influencia o entendimento e o sentimento de pertencimento deste. Dessa maneira, é salutar que haja um processo de educação cooperativista bem conduzido, de modo a evitar deficiências técnicas e riscos relacionais a uma avaliação equivocada de dirigentes politicamente hábeis, mas tecnicamente deficientes. A capacitação interna, que envolve liderança, habilidade para lidar com diferentes opiniões, visão sistêmica, zelo com a comunidade, interesse pelo próximo, compreensão dos valores cooperativistas, e pensamento sustentável, portanto, impactará na identificação do associado com a marca da instituição.

A utilização de um vocabulário específico tem a finalidade de deixar claras as informações as quais se discutem, como o processo de associação, por exemplo, que não se caracteriza somente pela abertura de uma conta, mas sim pela associação de um novo cooperado, que passa a compor o quadro societário da Cooperativa. A compra das quotas capital pode esclarecer o associado, uma vez que este novo integrante adquire uma quota-parte da instituição a qual será dono. É importante, portanto, desenvolver o processo de comunicação, que permeia todas as ações organizacionais, viabiliza a construção da cultura e identidade da organização, assim como de sua imagem externa (RESTREPO, 1995).

A questão da falta de participação dos associados da cooperativa estudada, e, consequentemente, do cumprimento de seus deveres e de suas responsabilidades, fundamenta-se em diferentes motivos. Além da falha no processo de educação do cooperado, justifica-se pela confusão entre bancos e cooperativas de crédito, desconhecendo a informação de que nelas eles têm determinadas atribuições, já que são seus quotistas e pela falta de interesse do associado, que busca na cooperativa apenas uma instituição financeira alternativa, com melhores taxas e menores custos, quando comparada às outras instituições. Tal postura deve ser desestimulada, visto que tais custos e taxas menores apenas são possíveis graças ao tipo do empreendimento, que não visa ao lucro.

Questões culturais também impactam na participação do associado. Isso se comprova quando comparamos a atuação dos associados paulistas à atuação dos associados paranaenses, catarinenses e rio-grandenses-do-sul. Estes, devido a fatores como a sua origem, de colonização holandesa e alemã, e sua educação, que tem o cooperativismo em sua grade desde o ensino fundamental, entendem os princípios cooperativistas, e, consequentemente, são mais participativos. Isto se deve, também, ao fato de que o cooperativismo de crédito brasileiro se originou no sul do país, mais precisamente no Estado do Rio Grande do Sul.

Nesse sentido, verifica-se que o perfil do associado paulista, também é um fator que impacta na participação, uma vez que se trata de um público de crédito comercial, que exige agilidade. Dessa forma, sua participação torna-se restrita às pequenas atividades, em detrimento de uma atuação ativa na cooperativa. Sua correção apoia-se na construção de um bom relacionamento com o associado, como também do desenvolvimento da educação cooperativista. É necessário fortalecer as relações entre este e a cooperativa para que ele sinta que faz parte do negócio e que é peça fundamental para seu desenvolvimento. Assim sendo, além da oferta de produtos de qualidade a preços competitivos cabe às cooperativas agir sempre de maneira sustentável e ética, para beneficiar todos os cooperados e também a sociedade como um todo (SERVIÇO NACIONAL DE APRENDIZAGEM DO COOPERATIVISMO, 2016).

A educação cooperativa, portanto, tem o importante papel de conscientizar o associado sobre sua relação com a sociedade cooperativa, seus direitos e deveres. Cientes do papel transformador do cooperativismo, haverá maior envolvimento e engajamento dos associados, maior senso de pertencimento, capacidade de conquistar novos associados e até a formação de novas lideranças para compor os órgãos de administração e fiscalização. 


\section{Conclusões}

Entendendo que a comunicação organizacional tem como objetivo primeiro o mercado, visando atingir os diversos públicos das corporações com o intuito de vender - seja uma imagem, seja um produto, seja uma ideia, seja uma fé - e obter lucro financeiro, pessoal, em status ou poder, verificou-se que o processo de comunicação da cooperativa estudada é deficitário.

A observação participante permitiu concluir que há pouco investimento na utilização de instrumentos e tecnologias de comunicação de massa, de grupo e interpessoal e que a comunicação organizacional, que abrange as diferentes formas de relacionamento e interação entre a organização e seus públicos, apresenta falhas tanto no que se refere à educação dos associados, à incapacidade dos colaboradores, quanto a unidade entre o sistema. Dessa maneira, não é possível vislumbrar resultados satisfatórios na formação de uma imagem positiva da organização diante de seu público, como forma de manutenção de seus negócios, o que evidencia sua importância em face do novo cenário globalizado (BRANDÃO, 2007).

Os resultados deste trabalho apontam que a comunicação, enquanto caracterizadora das operações próprias de cada organização, sua missão, seus valores, seus princípios e suas políticas, como divulgação, tornando-a pública, como gerador de relações voltadas a formação e a socialização e/ou reforço de processos culturais, como os programas Crescer e Pertencer, impacta na viabilização da construção da cultura e identidade da organização, assim como de sua imagem externa, de modo que esta caracteriza-se por não ser aquela almejada pelo sistema.

Consequentemente, a identidade organizacional, que é o resultado da relação produtiva entre discurso e imagem, ou seja, o que surge da afinidade entre as intenções do discurso e as impressões do receptor (LASBECK, 2007), torna-se comprometida ao seu receptor, o associado. Assim, para administrá-la, é importante coordenar a produção, a reprodução e a reformulação do discurso à vista dos dados obtidos pela pesquisa de imagem.

A construção da identidade, portanto, resulta dos esquemas cognitivos ou percepção a respeito dos atributos diferenciadores e essenciais da organização, incluindo seu posicionamento no contexto $\mathrm{e}$ comparações relevantes com outros grupos ou organizações, no caso, os bancos, instituições financeiras caracterizadas por serem sociedades de capital.

A imagem, por seu turno, que segundo Barich e Kotler (1991, apud BATISTA, 2004), representa a soma de crenças, atitudes, impressões que uma pessoa ou grupo tem de um objeto, torna-se distorcida na percepção do associado, o que impacta na sua visão da cooperativa, e, consequentemente, na sua utilização e sua participação. Percebe-se, então, que a imagem criada, fruto de uma impressão, é falsa ao que realmente é. Cabe, portanto, identificar as forças e fraquezas de sua imagem e empreender ações com a finalidade de melhorá-la. Este é um dos objetivos da nova marca, lançada no ano de 2017, que tem a finalidade de tornar o sistema Sicredi simples, ativo e próximo, contribuindo para desvincular as cooperativas aderidas ao sistema da ideia de um "mal necessário", como são vistos os bancos, para aproximar o Sistema do associado. Como consequência disso, a instituição deverá ser vista como uma opção para a vida financeira e não uma alternativa para a falta de opções.

Entendendo que diferentes pessoas podem ter diferentes imagens de uma mesma organização e que é o público quem detém a imagem da organização, é importante buscar alargar os espaços da identidade, que podem ser traduzidos por graus incertos e não totalmente previsíveis de afinidade entre produção e recepção, entre os interesses, desejos, e necessidades de quem os produz, o sistema Sicredi, e os interesses, desejos, e necessidades de quem os consome, os associados.

Sendo assim, atendendo aos seus objetivos, este trabalho demonstrou as distinções entre instituições financeiras cooperativas e bancos comerciais, identificando que a imagem percebida pelos associados da cooperativa estudada não é aquela almejada pelo Sistema. Verificaram-se falhas nos mecanismos de apresentação do Cooperativismo, como também em sua efetividade no contexto da cooperativa paulista. Identificou-se, ainda, que a comunicação organizacional interfere na imagem assimilada pelos associados, assim como as dificuldades na compreensão dos associados da cooperativa como sociedade de pessoas e não de capital.

Aferiu-se, outrossim, em contraposição ao que acontece em outras cooperativas que compõem o 
Sistema Sicredi, os motivos pelos quais há dificuldade em distinguir os bancos das cooperativas, demonstrando os direitos e deveres dos associados. Salienta-se, pois, a necessidade de mudança no comportamento das agências, desenvolvendo trabalhos que reforcem o relacionamento com os associados e que impactem na participação do destes, tornando-os mais próximos.

Esta mudança no comportamento das agências, também se refere à apreensão da marca, que possibilita ter colaboradores que sentem pertencer à instituição a qual se vinculam. Os programas de formação e qualificação Crescer e Pertencer e vivenciais possibilitam fazê-los compreender o espírito cooperativo, e assim participar mais, levando o colaborador e associados a se identificarem com o Sicredi.

Entre outras coisas, o associado deve estar ciente de que quanto mais utilizar a cooperativa, mais participativo e atuante ele for, mais ele contribuirá para o crescimento dela e para ampliar a divulgação dos princípios cooperativos. Como consequência, ele contribuirá para o crescimento de sua região, assim como para seu próprio crescimento. Por exemplo, quanto mais produtos e mais serviços da cooperativa forem utilizados, mais se contribuirá para o resultado financeiro dela e maior será a participação neste resultado, as sobras.

Ademais, "a educação cooperativista, como política institucional do segmento, pode ampliar a visibilidade do cooperativismo no Brasil e, consequentemente, colaborar para o crescimento sustentável das cooperativas de crédito" (SERVIÇO NACIONAL DE APRENDIZAGEM DO COOPERATIVISMO, 2016). Nesse sentido, é importante o fomento da cultura cooperativista estimulando à adesão de pessoas ao cooperativismo e ao cooperativismo de crédito.

O ex-presidente do Banco Central do Brasil, Alexandre Tombini, em depoimento dado por ocasião do lançamento da Agenda Legislativa do Cooperativismo, proclamou que "onde há presença forte do cooperativismo, há uma tendência de as tarifas financeiras e as taxas dos empréstimos serem menores do que nos municípios onde o cooperativismo de crédito não está presente. (Brasília/DF, em 28-02-2012). Cabe demonstrar, portanto, a capacidade do cooperativismo de crédito dentro de uma economia, ressaltando, todavia, que as instituições cooperativas não são apenas instituições financeiras alternativas, mas sim instituições atentas às expectativas do usuário, flexíveis, democráticas, promotoras do desenvolvimento local, comprometidas com o bem-estar econômico e social de seus associados e comunidades e tão (ou mais) seguras quanto os melhores bancos comerciais.

\section{Referências}

BAPTISTA GALVÃO, S. A importância do estudo sobre a imagem organizacional para as unidades de informação e para seus gestores. Biblios, Perú, vol. 5, n. 19, Abril-Septiembre, 2004. Disponível em: <http://www.redalyc.org/articulo.oa?id=161019 04>. Acesso em: 26 set. 2016.

BANCO CENTRAL DO BRASIL - BACEN. O que é cooperativa de crédito? Disponível em: <http://www.bcb.gov.br/pre/composicao/coopcr ed.asp>. Acesso em: 26 set. 2016. BRASIL.

BRANDÃO, E. P. Conceito de comunicação pública. In: DUARTE, Jorge. Comunicação pública: estado, mercado, sociedade e interesse público. São Paulo: Atlas, 2007.

CALDAS, M. P.; WOOD JÚNIOR., T. Identidade organizacional. Revista de Administração de Empresas, v. 37, n. 1, p. 6-17, jan.-mar, 1997.

CARDOSO, O. de O. Comunicação empresarial versus comunicação organizacional: novos desafios teóricos. Revista de Administração Pública, Rio de Janeiro, v. 6, n. 40, p. 1123-44, nov.-dez, 2006.

CARISSIMI, J. Reflexões sobre os processos organizacionais utilizados pelo Relações Públicas na construção da imagem organizacional. In: CONGRESSO BRASILEIRO DA COMUNICAÇÃO, 24, Anais..., Campo Grande. INTERCOM Sociedade Brasileira de Estudos Interdisciplinares da Comunicação, 2001. Disponível em: <http://www.geocities.ws/gestao2etcom/rp/refle xoes_sobre_processos.pdf $>$. Acesso em: 26 set. 2016. 
CHARAUDEAU, P. Discurso das mídias. São Paulo: Contexto, 2006.

CHIAVENATO, I. Introdução à teoria geral da administração. 7. ed. São Paulo: Elsevier: Campos, 2004.

FAVEIRO, M. H. A identidade e a imagem das organizações. Lusíada, v. Economia \& Empresa, II série, n. 2/3, 2003.

FERNANDES, M. E. R.; MARQUES, A. L.; CARRIERI, A. P. Identidade organizacional e os componentes do processo de identificação: uma proposta de integração. Cadernos EBAPE.BR, vol.7, n.4, pp.687-703, 2009.

FUNDAÇÃO SICREDI. A Trajetória do Sicredi: uma história de cooperação. Porto Alegre: Fundação Sicredi, 2014.

FUNDAÇÃO SICREDI. Programa Crescer. Disponível em: <https://crescer.sicredi.com.br/>. Acesso em: 30 out. 2016.

FUNDAÇÃO SICREDI. Programa Pertencer. Disponível em: <https://pertencer.sicredi.com.br/>. Acesso em: 30 out. 2016.

KOTLER, Philip. Princípio de marketing. 7. ed. Rio de Janeiro: Prentice-Hall do Brasil,1998.

KUNSCH, M. M. K. Relações públicas e modernidade: novos paradigmas na comunicação organizacional. São Paulo: Summus, 1997.

LASBECK, L. C. A. Imagem e reputação na gestão da identidade organizacional. Organicom, v. 4, número 7, 2007. Disponível em: <http://www.revistaorganicom.org.br/sistema/in dex.php/organicom/article/view/112/131>. Acesso em: 30 out. 2016.

LOPES, J. A. V. Cooperativismo contemporâneo: caminho para a sustentabilidade. Brasília: Confebras, 2012.
MACHADO-DA-SILVA, C.; NOGUEIRA, E. E. S. Instituições, Cultura e Identidade Organizacional. In: ENEO- ENCONTRO DE ESTUDOS ORGANIZACIONAIS, 1, Anais..., Curitiba. Anpad, 2000. Disponível em: $<$ http://www.anpad.org.br/admin/pdf/ene o2000-53.pdf >. Acesso em: 26 set. 2016.

MEINEN, E. O cooperativismo de crédito ontem, hoje e amanhã. Brasília: Confebras, 2012.

MITCHELL, W. J. T. Iconology: image, text, ideology. Chicago and London: The University of Chicago Press, 1986.

PORTAL DO COOPERATIVISMO FINANCEIRO. Dados consolidados dos sistemas cooperativos. Disponível em: $<$ http://cooperativismodecredito.coop.br/cenario -mundial/cenario-brasilei ro/dadosconsolidados-dos-sistemas-cooperativos/>. Acesso em: 2 out. 2016.

PORTAL DO COOPERATIVISMO FINANCEIRO. Sistema Sicredi. Disponível em: $<$ http://cooperativis modecredito.coop.br/cenario-brasileiro/sistemasicredi/>. Acesso em: 27 jan. 2016.

PROGRAMA de Formação Cooperativa Crescer: Cooperativismo de crédito: contribuindo para o crescimento coletivo. Porto Alegre: Fundação Sicredi, 2011.

PROGRAMA de Formação Cooperativa Crescer: Cooperativismo de crédito: compartilhando decisões e resultados. Porto Alegre: Fundação Sicredi, 2011.

RESTREPO, J. M. Comunicación para la dinâmica organizacional. Signo y Pensamiento. Colombia, v. 26, Universidad Javeriana: Facultad de Comunicación y Lenguage, p. 999196, 1995.

RIEL, Cees. B.M. Principles of corporate communication. Hemel Hempstead, Prenntice Hall, 1995.

RUÃO, T. O conceito de identidade organizacional: teorias, gestão e valor. In: CONGRESSO DA SOPCOM - ASSOCIAÇÃO PORTUGUESA 
DE CIÊNCIAS DA COMUNICAÇÃO, 02, Anais..., Lisboa. Fundação Calouste Gulbenkian, 2001. Disponível em: <https://repositorium.sdum.uminho.pt/bitstream/ 1822/2757/1/truao_IIS OPCOM_2001.pdf> Acesso em: 30 out. 2016.

RUÃO, T. O papel da identidade e da imagem na gestão das universidades. In: CONGRESSO DA SOPCOM - ASSOCIAÇÃO PORTUGUESA DE CIÊNCIAS DA COMUNICAÇÃO, 04, Anais..., Aveiro. Universidade de Aveiro, 2005. Disponível em: <http://repositorium.sdum.uminho.pt/bitstream/ 1822/5358/1/RuaoT_identidadimagemuniv_05. pdf>. Acesso em: 30 dez. 2016.

SERVIÇO NACIONAL DE APRENDIZAREM DO COOPERATIVISMO. Cooperativismo de crédito: boas práticas no Brasil e no mundo. Brasília: Farol. Estratégias em Comunicação, 2016.

SISTEMA OCB. Agenda Legislativa do Cooperativismo. Brasília: Sistema OCB, 2014. 